\section{In vitro pollination and fluorescence microscopy for characterization of gametophytic self- incompatibility of Coffea canephora Pierre ex A. Froehner}

\author{
Carolina Augusto de Souza ${ }^{{ }^{*}}$, Rodrigo Barros Rocha ${ }^{2}$, Maurício \\ Reginaldo Alves dos Santos ${ }^{2}$, Tatiane Almeida Lopes², \\ Alexsandro Lara Teixeira ${ }^{2}$ and Marcelo Curitiba Espindula ${ }^{2}$
}

\begin{abstract}
The objectives of this study were to optimize in vitro pollination and fluorescence microscopy procedures to characterize the gametophytic selfincompatibility of Coffea canephora genotypes. For that purpose, 115 in vitro pollinations were carried out among 30 parent plants of the Conilon (17) and Robusta (13) botanical varieties. Tester plants of compatibility groups I, II, and III were used as pollen grain donors. On the day of anthesis, pollen grains of the donor genotypes were transferred in vitro to one of the sides of the bifid stigma of each receptor flower. After 30 hours, the development of the pollen tubes was evaluated in fluorescence microscopy. Eleven genotypes (37\%) were classified in compatibility Group I, thirteen (43\%) in Group II, and six (20\%) in Group III. In vitro pollination allowed reduction in the time necessary to diagnose compatibility, without exhibiting contamination caused by the presence of pollen grains of non-donor plants.
\end{abstract}

Keywords: Canephora coffee, Conilon, Robusta, compatibility.

\section{INTRODUCTION}

The ability to impede self-fertilization is an important trait of the reproductive system of the Coffea canephora coffee plant, which evolved as a way of avoiding the harmful effects of inbreeding (Nowak et al. 2011). Self-incompatibility (SI) impedes a fertile plant from forming viable seeds when fertilized by its own pollen (Vieira et al. 2021).

C. canephora exhibits gametophytic self-incompatibility, and the incompatibility reaction occurs between the pollen tube and the style when they have the same allele (Coulibaly et al. 2002, Vieira et al. 2021). In this species, the expression of self-incompatibility is governed by only one multiallelic gene, identified by the letter $\mathrm{S}$. The action of ribonucleases degrades the ribosomal RNA in incompatible hybridizations, impeding growth of the pollen tube (Rêgo et al. 2000, Coulibaly et al. 2003).

Growing coffee through cloned plants that are not compatible can compromise coffee bean yield and quality from lower pollination efficiency and an increased rate of peaberries (Ferrão et al. 2017, Moraes et al. 2018). Although the incompatibility of $C$. canephora was already reported in the 1960 s, only a
Crop Breeding and Applied Biotechnology 21(4): e37692142, 2021 Brazilian Society of Plant Breeding. Printed in Brazil http://dx.doi.org/10.1590/198470332021v21n4a51 
few studies have focused on characterizing the compatibility of this species: Devreux et al. (1959) observed that after self-pollination, the pollen tube does not develop, preventing the pollen grain from arriving at the ovary. Conagin and Mendes (1961) and Berthaud (1980) found evidence that self-incompatibility in C. canephora must be governed by the action of a single $S$ gene, with three allelic forms $\left(\mathrm{S}_{1}, \mathrm{~S}_{2}, \mathrm{~S}_{3}\right)$. Omolaja and Fawole (2004) quantified the interaction of five allelic forms in expression of this trait. Lashermes et al. (1996) and Coulibaly et al. (2002) identified a molecular marker associated with this trait by development of doubled-haploid populations, homozygous for the $S$ gene, and showed that the development of the pollen tube can be observed using fluorescence microscopy. De Franceschi et al. (2012) described that the incompatibility is due to the interaction of specific glycoproteins on the flower stigma and on the pollen grains that combine to form dimers. Nowak et al. (2011) characterized the polymorphism of this gene among various species of the Coffea genus. More recently, Moraes et al. (2018) identified tester plants of three compatibility groups.

Characterization of compatibility in breeding programs depends on development of a method that considers the use of tester plants, sources of error, and ways to avoid them. Gregarious flowering, which occurs synchronously after periods of drought, results in high rates of field contamination, caused by pollen grains from non-donor plants that are transported by the wind and by insects (Prado et al. 2019).

In vitro pollination consists of transporting pollen grains in a controlled environment from the anthers of donor plants to the stigmas of receptor plants (Lashermes et al. 1996). This technique together with fluorescence microscopy techniques can potentially reduce the time for diagnosis of compatibility and allows greater precision in transferring pollen grains in directed hybridizations. The objectives of this study were to optimize in vitro pollination and fluorescence microscopy procedures to characterize the gametophytic self-incompatibility of $C$. canephora genotypes.

\section{MATERIAL AND METHODS}

\section{Tester plants and breeding population}

The compatibility response of each genotype was evaluated in relation to the tester plants. The genotypes BRS 1216 (Conilon Emcapa03 × Robusta1675), BRS 2299 (open pollination hybrid genotype), and BRS 3193 (open pollination hybrid genotype) were used as tester plants of compatibility groups I, II, and III, respectively (Moraes et al. 2018, Teixeira et al. 2020).

The breeding population consisted of thirty parent plants with characteristics of the Conilon and Robusta botanical varieties, grown in a hybrid production field set up in 2017 in the experimental field of Porto Velho, RO, Brazil. This breeding population was selected according to greater genetic divergence estimated from evaluation of agronomic and morphological descriptors over three years (Oliveira et al. 2018). The genotypes of the Conilon botanical variety were identified with the $\mathrm{C}$ prefix and the parent plants of the Robusta botanical variety were identified by the letter $\mathrm{R}$.

\section{In vitro pollination}

In vitro pollination consisted of transfer of pollen grains from donor plants to stigmas of receptor plants, performed in the laboratory. In the experimental field of Embrapa Rondônia in the municipality of Porto Velho, RO, flowering was monitored weekly from January to December 2019. The smaller number of pollen grains and flowers necessary for in vitro pollination allows a larger number of hybridizations to be performed over the crop year. In vitro pollination procedures were performed on five different occasions: 17 May 2019, 5 Jun. 2019, 4 Jul. 2019, 31 Jul. 2019, and 9 Sep. 2019, for a total of 115 directed hybridizations, with $12,28,35,22$, and 18 hybridizations performed on each date, respectively.

Prior to in vitro pollination, germination tests of the pollen grains were performed for each donor plant in $10 \%$ sucrose solution (Owuor 1985). To facilitate detachment of the pollen grains, the anthers were immersed in $5.0 \mathrm{ml}$ of $10 \%$ sucrose solution in Eppendorf type tubes (Figure 1). Using a pipettor, the solution containing pollen grains was distributed in a homogeneous manner on a Petri dish. After 60 minutes, using a stereoscopic microscope (50x magnification), three replicates of 100 pollen grains were counted for each pollen donor. The pollen grains whose pollen tube length was greater than the pollen grain diameter were considered germinated. Mean germination rates greater than $60 \%$ indicate good pollen grain viability (Owuor 1985) (Figure 1).

On the day before anthesis, at around 4:00 pm, inflorescences of the receptor and donor plants (testers) were collected, which were placed in paper bags and taken to the Plant Tissue Culture Laboratory of Embrapa Rondônia. 
Stamens and petals of the receptor flowers were removed and the inflorescences, containing three, four, or five flowers, were placed in containers with solid culture medium (water, $30 \%$ sucrose, $6 \%$ bacteriological agar, $1 \%$ amoxicillin), with the peduncle immersed in culture medium. The culture medium can be autoclaved and stored; it is not necessary to correct its $\mathrm{pH}$ (Torres et al. 1998). After exposure to the environment, the antibiotic culture medium is viable for approximately four days, enough time for the development of pollen tubes, which require approximately 36 hours.

Inflorescences of the donor plants, with buds still closed, were placed in containers with the same culture medium, with the peduncle immersed in the medium (Figure 2). After that, all the containers were sealed with plastic film to prevent contamination by pollen grains and kept in a plant growth room at $26 \pm 1^{\circ} \mathrm{C}$ and 16-hour photoperiod $\left(50 \mu \mathrm{moL} \mathrm{m} \mathrm{L} \mathrm{s}^{-1}\right)$.

Each compatibility diagnosis is based on the evaluation of 10 stigmas pollinated on one of the tips of the bifid stigma. On the day of anthesis, the pollen grains were collected from the donor flowers by scraping the dehiscent anthers with a scalpel. Scraping should be carried out until the pollen grains are visible to the naked eye on the scalpel. The scalpel blade, full of pollen grains, was then delicately rubbed on one of the tips of the bifid stigma, leading to adherence of the pollen grains on the stigma (Figure 2 ).

\section{Fluorescence microscopy}

The diagnosis of compatibility is based on visualization of the development of the pollen tubes in the pistil of the compatible plants. Thirty-six (36) hours after pollination, the stigmas were stored in FAA solution (10\% formaldehyde, 10\% glacial acetic acid, and $80 \%$ ethanol), using penicillin vials $(10 \mathrm{~mL})$ with a rubber lid (Coulibaly et al. 2002). The samples were then stored in a refrigerator at $5^{\circ} \mathrm{C}$ until preparation of the slides.

For preparation of the slides, the pistils were removed from the FAA, washed with distilled water, and immersed in sodium hydroxide ( $1 \mathrm{~N} \mathrm{NaOH}$ ) for 2 hours. After that period, the stigmas were washed with distilled water and stained for 12 hours using $1 \%$ aniline blue stain prepared in a $0.1 \mathrm{M} \mathrm{K}_{2} \mathrm{PO}_{4}$ solution. After that the stigmas were once more washed with distilled water. The sodium hydroxide solution causes alkaline hydrolysis of the ester type covalent bonds between the lignin and the structural carbohydrates of the cell wall with solubilization of the hemicellulose and phenolic compounds (Tarkow and Feist 1969).

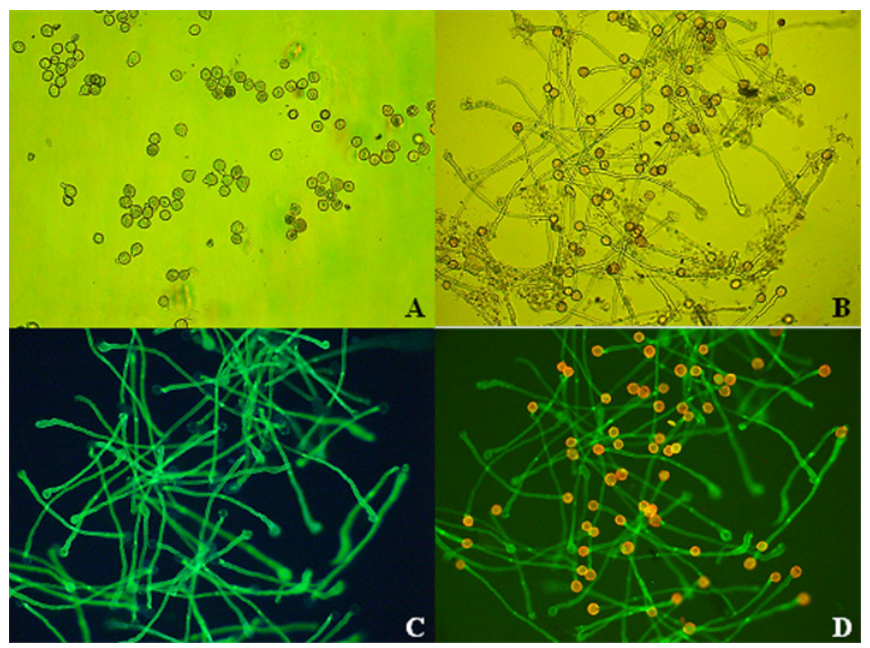

Figure 1. Pollen grains in culture medium at the time of transfer under white light (100x) (A), germination of pollen grains in culture medium 10 minutes after transfer under white light (100x) (B), germination of pollen grains in culture medium 10 minutes after transfer under fluorescence (100x) (C and D).

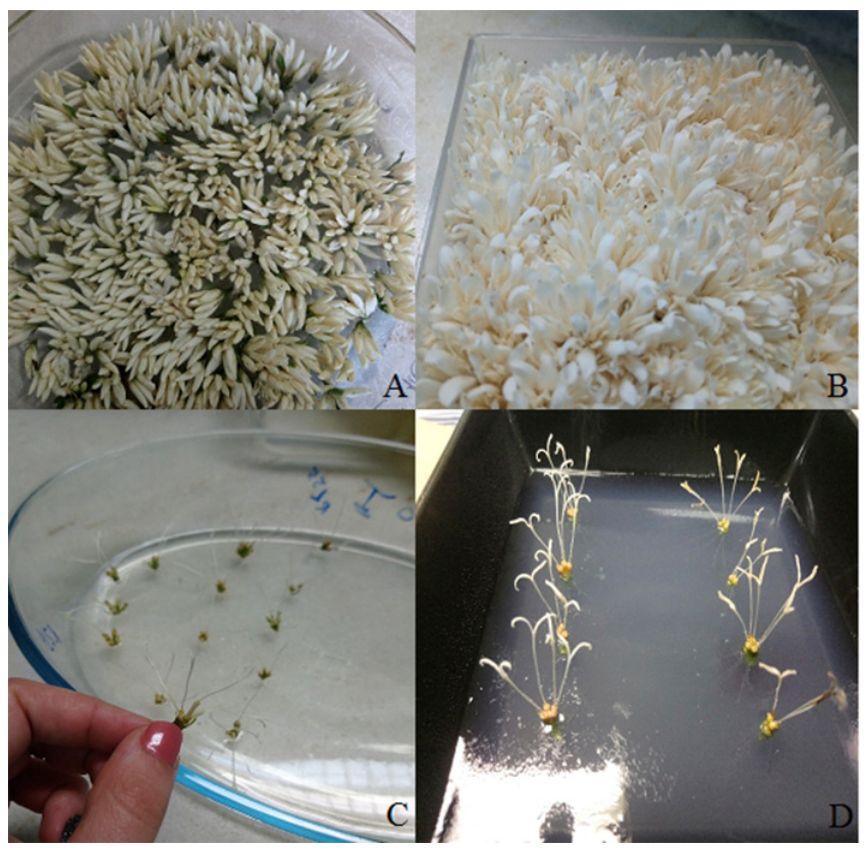

Figure 2. Method for in vitro pollination: A. Flower of the donor clone (male) collected one day before anthesis. B. Flower of the donor clone 3 hours after opening in the culture medium. C. Flower of the receptor botanical variety removing the male part. D. Receptor flower in vitro. 
For visualization, ten pistils were placed on each slide, and a coverslip was delicately pressed on the pistils to flatten them on the slide. The material was visualized using a Leica DM2500 microscope, equipped with a photodocumentation system. The pistils were visualized in $100 x$ and $200 x$ magnification, counting the number of pistils that had completely developed pollen tubes (Figure 3 ).

Ten stigmas were evaluated for each directed hybridization, and the crosses that exhibited pollen tubes that were completely developed in the style of the stigma were considered compatible (Figure 4). Pollination efficiency (Ep) was estimated from the ratio between the number of pollinated stigmas (NPS) and the total number of stigmas (TNS).

In diagnosis of compatibility, it is important to consider that each procedure has a probability of error, due to the conditions of handling the material or the environment. The in vitro pollination procedures allow the transfer of pollen grains to be precisely controlled, avoiding false positive diagnoses that occur when two genotypes are incorrectly considered compatible, due to contamination. False negative type errors can also occur, when two genotypes are considered incompatible, due to some failure in the procedure. Thus, for diagnosis of compatibility, an error rate of $5 \%$ was considered in each procedure.

\section{RESULTS AND DISCUSSION}

The use of tester plants for determination of compatibility groups is based on evaluation of the compatibility response in comparison to a plant of known genotype for the $S$ gene. Under this same principle, tester plants of $C$. canephora have been used for identification of rust (Hemileia vastatrix) races, since the resistance response is also governed by few genes of greater effect (Pereira et al. 2020).

This method allows reduction in the number of hybridizations ( $n$ ) necessary for diagnosis of compatibility of $g$ genotypes from $n$. $(n-1) / 2$ to $n . t$, where $t$ is the number of tester plants. Thus, the characterization of compatibility of 30 genotypes in relation to 3 tester plants requires 90 hybridizations, which represents a reduction of $79 \%$ in comparison to the number of 435 hybridizations necessary for characterization of compatibility among 30 genotypes without the use of tester plants.

The genealogy of the $S$ gene in C. canephora progenies grown in the North region of Brazil was characterized by Moraes et al. (2018), who clustered the genotypes in three different compatibility groups. The clones BRS1216, BRS2299, and BRS3193, used as tester plants in our study, belong to compatibility groups I, II, and III, respectively.

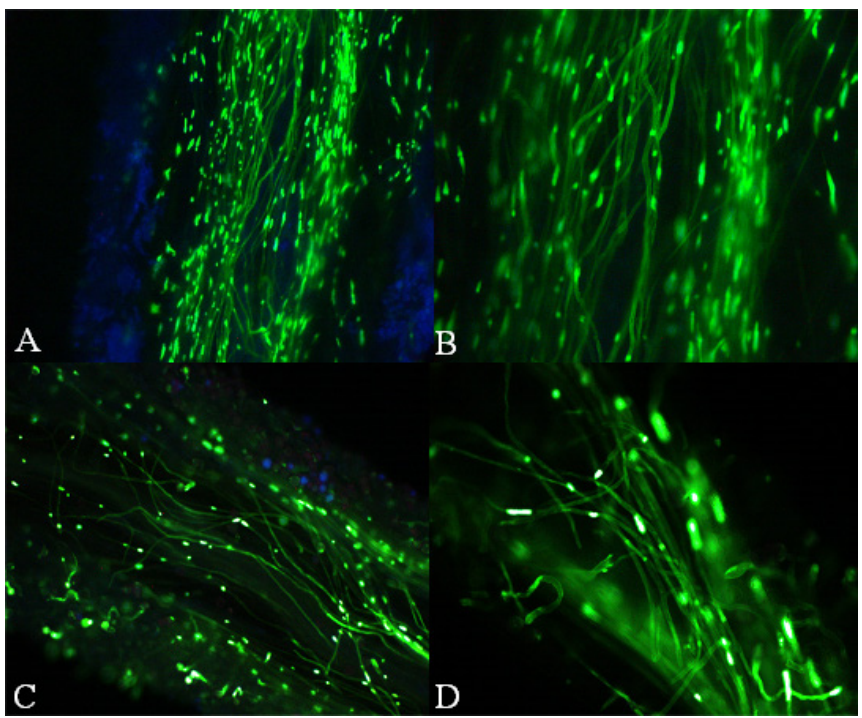

Figure 3. Developed pollen tubes visualized in the stigmas of compatible receptor plants using fluorescence microscopy 30 hours after in vitro pollination ( $A$ and $C-200 x, B$ and $D-400 x$ ).

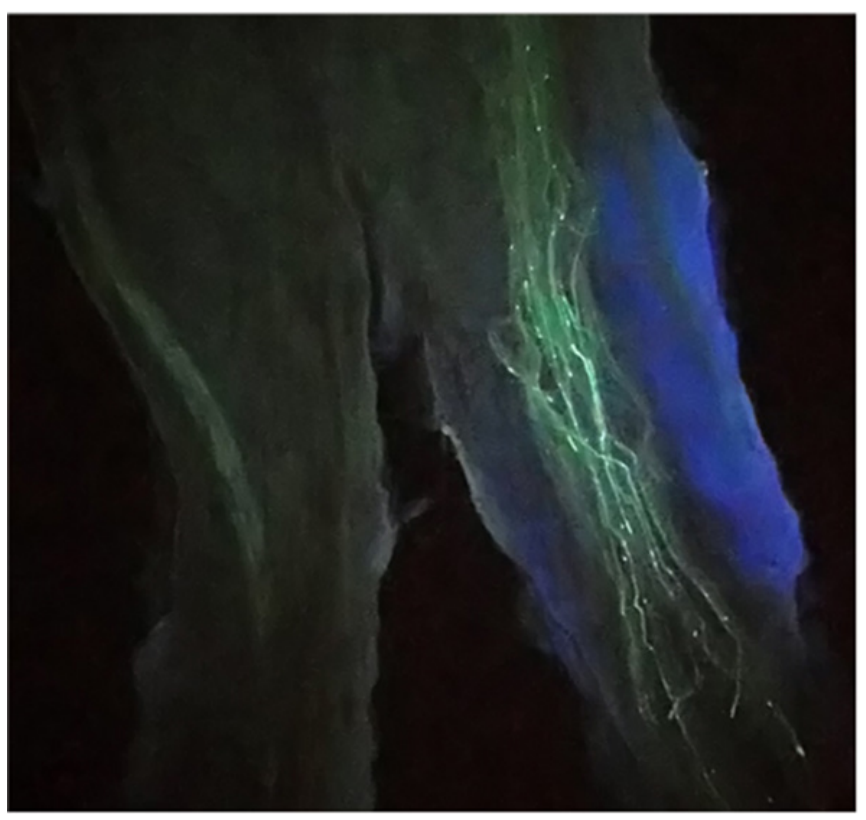

Figure 4. Pollination of only one of the sides of the bifid stigma favors visualization under the microscope by the contrast between the pollinated and non-pollinated styles. 
In vitro pollination and fluorescence microscopy for characterization of gametophytic self-incompatibility of Coffea canephora...

Receptor flowers and donor flowers should be collected one day before anthesis, at the end of the afternoon, avoiding contamination of pollen grains among the donor genotypes. Inflorescences in the same phase of development, characterized by well-developed flower buds, should be chosen at the time of collection (Prado et al. 2019).

Under in vitro conditions, anthesis may take a little longer to occur compared to field conditions, in which flower opening occurs beginning in the early morning hours, positively affected by environmental temperature (Peters and Carroll 2012). In vitro anthesis can occur in an interval of up to 48 hours, a period in which the stigmas remain receptive in the culture medium.

The viability of the pollen grains should be evaluated prior to the transfer of the pollen grains from the donor genotype to the receptor genotypes. The donor genotype BRS 1216 exhibited a mean germination rate of $60 \%$, ranging from $40 \%$ to $75 \%$ in the five trials performed in the year 2019. The genotype BRS 2299 exhibited a mean germination rate of $80 \%$, with amplitude from $70 \%$ to $95 \%$, and the genotype BRS 3193 exhibited a mean of $75 \%$, with amplitude from $60 \%$ to $90 \%$. These values indicate good pollen viability. Walyaro and Vossen (1977) evaluated the germination of pollen grains stored in a freezer under vacuum conditions at $-18{ }^{\circ} \mathrm{C}$ and observed that viability declined to $70 \%$ in 9 months, and to $60 \%$ in 11 months. Conagin and Mendes (1961) observed that germination rates lower than $55 \%$ were associated with lower viability of $C$. canephora pollen grains.

Pollination of only one of the sides of the bifid stigma favors visualization under the microscope by the contrast between the pollinated and non-pollinated styles (Figure 4). In compatible crosses, the pollen grains that adhere to the stigma germinate, forming a pollen tube that grows into the style. The pollen tube is an elongation of the cell of the pollen grain that grows chemotropically in the direction of the ovary carrying the vegetative and germinative nuclei (Fu and Yang (2014).

Aniline blue has great affinity to callose, a polysaccharide presents in lower concentration in cell walls and in greater concentration around the androspores during meiosis, allowing identification of the compatible hybrids through the contrast of the pollen tubes (Coulibaly et al. 2002). During slide preparation, previous immersion in $1 \mathrm{~N} \mathrm{NaOH}$ solution results in softening of the cell wall of the pistil, which is essential both for fixing the stain and for crushing the tissue in setting up the slides.

In in vitro pollinations between compatible genotypes, a pollination efficiency of $41.7 \%$ was observed, with amplitude from $12 \%$ to $90 \%$. The pollination efficiency of in vitro pollination (measured from the ratio between the number of pollinated stigmas and the number of fertilized stigmas) was comparable with the fruit set rates observed in the field in other studies. In evaluation of 80 directed hybridizations performed in the field, Moraes et al. (2018) observed a mean fruit set rate of $44 \%$, with amplitude from $26 \%$ to $77 \%$. The same authors observed contamination in non-compatible crosses, with mean rates higher than $10 \%$. Visualization of pollen tube development using fluorescence microscopy also allows reduction in the time necessary for diagnosis of compatibility (Figure 3).

Of the total of 115 directed hybridizations performed in five different seasons of the year, compatible crosses predominated (81\%) (Table 1). According to Falconer and Mackay (1996), the mechanism of determination of compatibility places the $S$ gene over negative selection dependent on frequency, which means that the frequency of an allele is inversely proportional to its adaptive value. In other words, the individuals in a population that are carriers of rarer allelic forms of this gene benefit from greater frequency of potential pollen donor plants, making the fertilization rate of an individual inversely proportional to the frequency of the allele in the population.

The genotypes evaluated in this study were selected from a hybridization field containing parent plants of the Conilon and Robusta botanical varieties. Although more recent studies of genetic mapping and of functional genomics have not shown evidence of connection between yield characteristics and the $S$ gene (Lashermes et al. 1996, Nowak et al. 2011), it should be considered that through chance and sampling errors, selection may reduce the variability of this gene.

From visualization of the development of the pollen tubes, the compatibility of 30 genotypes was evaluated, which clustered in three compatibility groups ( 11 genotypes clustered in compatibility group I, 13 genotypes in compatibility group II, and 6 genotypes in compatibility group III) (Table 2). Conagin and Mendes (1961) and Moraes et al. (2018) also reported the occurrence of 3 compatibility groups. On the African continent, the center of origin of this species, Omolaja and Fawole (2004) observed six compatibility groups. Knowledge of the compatibility groups allows new clonal crops 
Table 1. Summary of the hybridizations performed of 30 genotypes with tester plants of the compatibility groups I, II, and III. The non-compatible hybridizations are indicated by the number within parentheses, and the compatible hybridizations are indicated by the numbers without formatting

\begin{tabular}{|c|c|c|c|c|c|c|c|c|}
\hline \multirow{2}{*}{ n } & \multirow{2}{*}{ Clone } & \multicolumn{3}{|c|}{ Tester hybridizations } & \multirow{2}{*}{ FN } & \multirow{2}{*}{ FP } & \multirow{2}{*}{ Group } & \multirow{2}{*}{$p$ value } \\
\hline & & 1 & II & III & & & & \\
\hline 1 & C 125 & 2 & (1) & 2 & 0 & 0 & II & 0.05 \\
\hline 2 & C 154 & $(2)$ & 1 & 1 & 0 & 0 & 1 & 0.05 \\
\hline 3 & C 167 & (1) & 1 & 1 & 0 & 0 & 1 & 0.05 \\
\hline 4 & C 184 & 1 & (1) & 1 & 0 & 0 & II & 0.05 \\
\hline 5 & C 452 & (2) & 1 & 1 & 0 & 0 & 1 & 0.01 \\
\hline 8 & C 484 & 1 & 1 & (1) & 0 & 0 & III & 0.05 \\
\hline 9 & C 59 & 1 & (1) & 1 & 0 & 0 & II & 0.05 \\
\hline 10 & C 694 & 2 & 1 & (1) & 0 & 0 & III & 0.05 \\
\hline 11 & C 729 & 1 & (1) & 2 & 1 & 0 & II & 0.05 \\
\hline 12 & С 795 & 1 & (1) & 1 & 1 & 0 & II & 0.05 \\
\hline 16 & C 968 & 1 & 1 & (1) & 0 & 0 & III & 0.05 \\
\hline 17 & C 986 & (1) & 1 & 1 & 0 & 0 & 1 & 0.05 \\
\hline 18 & R 164 & 2 & 2 & (1) & 0 & 0 & III & 0.01 \\
\hline 19 & R 183 & (1) & 2 & 1 & 1 & 0 & 1 & 0.05 \\
\hline 20 & R 214 & (1) & 1 & 1 & 0 & 0 & 1 & 0.05 \\
\hline 21 & R 216 & (1) & 1 & 1 & 1 & 0 & 1 & 0.05 \\
\hline 22 & R 277 & 1 & (1) & 1 & 0 & 0 & II & 0.05 \\
\hline 23 & R 3 & (1) & 1 & 2 & 0 & 0 & 1 & 0.05 \\
\hline 24 & R 30 & (1) & 4 & 1 & 0 & 0 & 1 & 0.05 \\
\hline 25 & R 32 & 3 & 1 & (2) & 0 & 0 & III & 0.05 \\
\hline
\end{tabular}

$\mathrm{n}$ : ordinal numbering of the receptor clones evaluated; Genotype: numbering of the genotype in the Embrapa coffee breeding program; I: compatibility group I (one); II: compatibility group II (two); compatibility group III (three); FN: hybridizations with false negative type error; FP: hybridizations with false positive type error; Group: diagnosis of the compatibility group; and $p$ value: probability of error of classification of the genotype in its respective compatibility group considering a $5 \%$ error rate.

to be established in the search for greater pollination efficiency (Rocha et al. 2015).

Two types of error can occur in determination of compatibility: type I error, called false positive, which occurs due to contamination of pollen grains from other plants, and type II error, called false negative, which occurs due to a failure in the procedure (Table 3).

Pollination performed in vitro allows control of the pollen grains used in the hybridizations in an aseptic environment, preventing contamination that could lead to what is called a false positive. The false negative error, for its part, can occur through various factors, including the viability of the pollen grains, maturity of the stigmas, and ability and care during manual pollination.
Table 2. Efficiency and error rate of in vitro pollination considering the number of hybridizations performed with tester plants of the compatibility groups (I, II, and III)

\begin{tabular}{lcccc}
\hline In vitro pollination & I & II & III & Total \\
\hline Compatible hybridizations & 27 & 22 & 30 & 79 \\
Non-compatible hybridizations & 14 & 13 & 9 & 36 \\
\hline Total hybridizations & 41 & 35 & 39 & 115 \\
\hline False negative & 4 & & \\
False positive & 0 & & \\
False negative rate & 3.45 & & \\
\hline
\end{tabular}

I: compatibility group I, II: compatibility group II, III: compatibility group III. 
In vitro pollination and fluorescence microscopy for characterization of gametophytic self-incompatibility of Coffea canephora...

Table 3. Description of the most important sources of error and forms of control for diagnosis of compatibility using in vitro pollination and fluorescence microscopy

\begin{tabular}{|c|c|c|}
\hline Type of error & Source of error & Form of control \\
\hline \multirow{3}{*}{$\begin{array}{l}\text { False } \\
\text { negative }\end{array}$} & Viability of the pollen grains & Performance of germination test prior to in vitro pollination \\
\hline & Transfer of the pollen grains & Training for development of manual ability in scraping pollen grains \\
\hline & Stigma maturity & $\begin{array}{l}\text { Collection of stigmas in the field and transfer to the culture medium on the day before } \\
\text { anthesis }\end{array}$ \\
\hline \multirow[b]{2}{*}{ False positive } & Contamination of pollen grains & Use of asepsis procedures during in vitro pollination \\
\hline & Mistaken diagnosis & Training for visual recognition of the pollen tubes Careful preparation of the slides \\
\hline
\end{tabular}

As self-incompatibility is a pre-zygotic mechanism that affects the fertility rate of pollen grains, it is an important factor for the variability of natural populations. However, it can limit plant selection, which should consider the cultivation of compatible clones and greater field pollination efficiency.

Although the visualization of coffee pollen tubes has been a known technique since the 1990s, the optimizations presented in this study support the diagnosis of compatibility in the routine of breeding programs, considering the use of tester plants, control of sources of error, possibility of evaluations at different times of the year, and shorter diagnostic time, since this technique does not depend on the development of fruit in the field.

Considering that the expression of self-incompatibility is governed by a single gene, with little or no environmental effect, the characterization of self-incompatibility has the potential to identify new allelic forms and new compatibility groups, supporting better pollination efficiencies in coffee plantations.

\section{CONCLUSIONS}

In vitro pollination methods led to an increase in pollination efficiency, without exhibiting contamination caused by the presence of pollen grains of non-donor plants. The use of fluorescence microscopy allowed reduction in the time necessary to diagnose compatibility in hybridizations. The germination test allowed identification of pollen viability. Of the 30 genotypes, 11 clustered in compatibility group I, 13 in compatibility group II, and 6 in compatibility group III.

\section{ACKNOWLEDGMENTS}

The authors thank CNPq (Conselho Nacional de Desenvolvimento Científico e Tecnológico) and CAPES (Coordenação de Aperfeiçoamento de Pessoal de Nível Superior - Brasil - Finance Code 001) for granting scholarships. They are also grateful to CPC (Consórcio Brasileiro de Pesquisa e Desenvolvimento do Café) and to FAPERO (Fundação Rondônia de Amparo ao Desenvolvimento das Ações Científicas e Tecnológicas e à Pesquisa do Estado de Rondônia) for financial support.

\section{REFERENCES}

Berthaud J (1980) L'incompatibilité chez Coffea canephora: méthode de test et déterminisme génétique. Café Cacao Thé 24: 267-274.

Conagin C and Mendes A (1961) Pesquisas citológicas e genéticas em três espécies de Coffea canephora Pierre ex Froehner. Bragantia 20: 787-804.

Coulibaly I, Noirot M, Lorieux M, Charrier A, Hamon S and Louarn J (2002) Introgression of self-compatibility from Coffea heterocalyx to the cultivated species Coffea canephora. Theoretical and Applied Genetics 105: 994-999.

Coulibaly I, Revol B, Noirot M, Poncet V, Lorieux M, Carasco-Lacombe C, Minier J, Dufour M and Hamon P (2003) AFLP and SSR polymorphism in a Coffea interspecific backcross progeny [(C. heterocalyx $\times C$. canephora) $\times$ C. canephora]. Theoretical and Applied Genetics 107:
$1148-1155$

De Franceschi P, Dondini L and Sanzol J (2012) Molecular bases and evolutionary dynamics of self-incompatibility in the Pyrinae (Rosaceae). Journal of experimental botany 63: 4015-4032.

Devreux M, Vallaeys G, Pochet P and Gilles A (1959) Recherches sur l'autosterilité du caféier robusta (Coffea canephora Pierre). Série Scientifique 78: 1-44.

Falconer DS and Mackay TFC (1996) Introduction to quantitative genetics. Longman Group Limited, Edinburgh, 463p.

Ferrão MAG, Souza EMR, Fonseca AFA and Ferrão RG (2017) Autoincompatibilidade e produção sustentável do café Conilon. In Ferrão RG, Fonseca AFA, Bragança SM, Ferrão MAG and Muner LH (eds) Café Conilon. Incaper, Vitória, p. 177-191.

Fu Z and Yang P (2014) Proteomics advances in the understanding of 
pollen-pistil interactions. Proteomes 2: 468-484.

Lashermes P, Couturon E, Moreau N, Paillard M and Louarn J (1996) Inheritance and genetic mapping of self-incompatibility in Coffea canephora Pierre. Theoretical and Applied Genetics 93: 458-462.

Moraes MS, Teixeira AL, Ramalho AR, Espindula, MC, Ferrão, MAG and Rocha RB (2018) Characterization of gametophytic selfincompatibility of superior clones of Coffea canephora. Genetics and Molecular Research 17: 1-11.

Nowak MD, Davis AP, Anthony F and Yoder AD (2011) Expression and trans-specific polymorphism of self-incompatibility RNases in Coffea (Rubiaceae). PloS One 6: e21019.

Oliveira LNL, Rocha RB, Ferreira FM, Spinelli VM, Ramalho AR and Teixeira AL (2018) Selection of Coffea canephora parents from the botanical varieties Conilon and Robusta for the production of intervarietal hybrids. Ciência Rural 48: 1-7.

Omolaja S and Fawole I (2004) Determination of the number of selfincompatibility alleles (SIA) in Coffea canephora and the role of pollen-stylar protein in the expression of SIA. In ASIC 2004 20th international conference on coffee science. Omolaja $S$ and Fawole I, Bangalore, p. 11-15.

Owuor J (1985) Interspecific hybridization between Coffea arabica L. and tetraploid C. canephora P. Ex Fr. II. Meiosis in $F_{1}$ hybrids and back crosses to C. arabica. Euphytica 34: 355-360.

Pereira DR, Nadaleti DH, Rodrigues EC, Silva AD, Malta MR, Carvalho SP and Carvalho GR (2020) Genetic and chemical control of coffee rust (Hemileia vastatrix B erk et B r.): impacts on coffee (Coffea arabica L.) quality. Journal of the Science of Food and Agriculture 1: 1-10

Peters VE and Carroll CR (2012) Temporal variation in coffee flowering may influence the effects of bee species richness and abundance on coffee production. Agroforestry Systems 85: 95-103.

Prado SG, Collazo JA, Stevenson PC and Irwin RE (2019) A comparison of coffee floral traits under two different agricultural practices. Scientific Reports 9: 1-13.

Rêgo M, Rêgo E, Bruckner C, Silva E, Finger F and Pereira K (2000) Pollen tube behavior in yellow passion fruit following compatible and incompatible crosses. Theoretical and Applied Genetics 101: 685-689.

Rocha RB, Ramalho AR, Teixeira AL, Souza FDF and Cruz CD (2015) Adaptabilidade e estabilidade da produção de café beneficiado em Coffea canephora. Ciência Rural 45: 1531-1537.

Tarkow H and Feist WC (1969) A mechanism for improving the digestibility of lignocellulosic materials with dilute alkali and liquid ammonia. Advances in Chemistry 95: 197-218.

Teixeira AL, Rocha RB, Espindula MC, Ramalho AR, Vieira Júnior JR, Alves EA, Lunz AMP, Souza FF, Costa JNM and Fernandes CF (2020) Amazonian Robustas-new Coffea canephora coffee cultivars for the Western Brazilian Amazon. Crop Breeding and Applied Biotechnology 20: e323420318.

Torres AC, Caldas LS and Buso JA (1998) Cultura de tecidos e transformação genética de plantas. Embrapa-SPI and EmbrapaCNPH, Brasília, 345p.

Vieira J, Pimenta J, Gomes A, Laia J, Rocha S, Heitzler P and Vieira CP (2021) The identification of the Rosa S-locus and implications on the evolution of the Rosaceae gametophytic self-incompatibility systems. Scientific Reports 11: 1-12.

Walyaro D and Vossen HVD (1977) Pollen longevity and artificial crosspollination in Coffea arabica L. Euphytica 26: 225-231.

(cc) EY This is an Open Access article distributed under the terms of the Creative Commons Attribution License, which permits unrestricted use, distribution, and reproduction in any medium, provided the original work is properly cited. 